\title{
ЗАКЛЮЧЕНИЕ ДОГОВОРА ДОЛЕВОГО УЧАСТИЯ В УСЛОВИЯХ РАЗВИТИЯ ЦИФРОВОГО ПРОСТРАНСТВА
}

\section{CONCLUSION OF AN EQUITY PARTICIPATION AGREEMENT IN THE CONTEXT OF THE DEVELOPMENT OF DIGITAL SPACE}

\section{A. Ivanov}

Summary. In the information economy, in the context of digitalization of workflow, optimization of the interaction processes of participants in real estate transactions under the conditions of restrictions associated with COVID-19, the possibilities of electronic forms of concluding an equity participation agreement are being actively discussed and developed, which will not replace or eliminate the traditional agreement in paper form. The main direction here remains security, consisting in the collection of information, preparation of documents and online interaction of the parties to the transaction in electronic digital formats, using an electronic digital signature.

Taking into account the goals of civil law regulation of shared construction, these developments should ensure both the implementation of the rights and legitimate interests of the participants in transactions and the public interest, which requires appropriate legal regulation.

Keywords: equity participation agreement, electronic agreement, digitalization, remote work, electronic digital signature.

\author{
Иванов Алексей Алексеевич \\ Московский университет МВД России имени \\ В.Я. Кикотя \\ ExeleX001@mail.ru
}

Аннотация. В информационной экономике, в условиях цифровизации документооборота, оптимизации процессов взаимодействия участников сделок по недвижимости в условиях ограничений, связанный с COVID-19, активно обсуждаются и разрабатываются возможности электронных форм заключения договора долевого участия, которые не заменят и не устранят традиционный договор в бумажной форме. Основным направлением здесь остается обеспечительное, состоящее в сборе информации, подготовке документов и онлайн взаимодействии участников сделки в электронных цифровых форматах, с использованием электронной цифровой подписи.

Принимая во внимание цели гражданско-правового регулирования долевого строительства, эти разработки должны обеспечить как реализацию прав и законных интересов участников сделок, так и публичный интерес, что требует соответствующего правового регулирования.

Ключевые слова: договор долевого участия, электронный договор, цифровизация, удаленная работа, электронная цифровая подпись.

масштабов и сложности «строительного бизнеса», который, по их оценке, «по объемам обрабатываемой информации и документообороту, не уступает крупным производствам». Именно поэтому, авторы считают необходимым разработку подходов к заключению ДДУ «В электронном формате» [2, с.71]. Указанный подход представляется ограниченным, сугубо техническим и исходящим исключительно из отраслевого подхода.

Гражданско-правовое регулирование во всех сферах, в том числе и долевого строительства, направлено на предоставление возможностей наиболее полной реализации прав и достижения законных интересов участников. В этой связи вопрос заключения договоров В электронной форме приобретает существенно более широкое, не обусловленное лишь потребностями строительной отрасли, значение. Такой договор защищает интересы покупателя, поддерживает устойчивость и прозрачность рынка недвижимости. Помимо чисто правовых аспектов оно включает также и возможности 
участия искусственного интеллекта в подготовке, оценке и мониторинге ДДУ, применении смарт-контактов для их согласования и заключения [3, с. 251].

В условиях ограничений, связанных с пандемией, эти направления развития приобрели особую актуальность. В 2020 г. рынок недвижимости, как многие другие сектора экономики, в какой-то части ушел на удаленный режим работы. В онлайн режиме проходили просмотры объектов, рассматривались вопросы подготовки сделок.

Работа в условиях частичной пандемической изоляции, вынуждено «органично» вписалась в процессы цифровизации, несколько расширив сферу её применения и стимулировав разработку новых продуктов и инновационных решений, которые призваны оптимизировать не только делопроизводственные, но и некоторые юридические процессы. Такое развитие сложно считать революционным, так как подготовка к цифровизации активно шла и до пандемии. В частности, Сбербанк одним из первых внедрил подписание договоров долевого участия с помощью электронной цифровой подписи (далее - ЭЦП), что позволяет минимизировать время и продолжительность сделки. В то же время ЭЦП оформляется платно и поэтому, если ранее она не была оформлена у участника сделки, это может повлиять на общую стоимость. Для устранения этого (с позиции покупателя) недостатка, Сбербанк предоставляет заемщикам, которые воспользовались ЭЦП для оформления ДДУ освобождение от внесения государственной пошлины. Также и Росреестр дает 30\%-ную скидку при использовании электронной подачи документов на сделку. Таким образом, цифровые технологии распространяются на вспомогательные (подготовительные) и обеспечивающие процессы заключения ДДУ. Сюда следует включить всю совокупность документов, удостоверяемых ЭЦП. Это широкая совокупность бланков и форм, связанных со сделкой, соглашение покупателя и застройщика, копия паспорта заявителя с отметкой о его семейном положении; нотариально заверенное согласие одного из супругов, заявление на государственную регистрацию в Росреестр и др.

При этом следует иметь ввиду, что совершение сделки с использованием ЭЦП не предполагает наличие документов, составленных в традиционной, заверенной подлинными подписями, письменной форме. В случае спора электронный формат доказательств, трудно использовать.

Другой формой цифровизации является типовая регистрация ДДУ путём внесения сведений о договоре в базу Росреестра, что позволяет минимизировать потенциальные противоправные действия застройщика, которому, в частности, при наличии соответствующе- го умысла, не удастся легально продать несколько раз один объект.

На какие сферы, помимо подготовки и заверения документов ЭЦП, может быть распространена электронная форма? Этот вопрос, особенно в условиях затяжных пандемических ограничений и связанных с ними удаленных форматов работы, имеет сегодня особую актуальность.

Действующее гражданское законодательство (ст. 434 ГК РФ) дает возможность хозяйствующим субъектам (юридическим и физическим лицам, а также некоммерческим организациям, ведущими от своего имени экономическую деятельность) заключать договоры путем обмена электронными документами [4]. Таким образом, ГК РФ предусматривает скорее не форму, а электронный, процесс заключения договоров.

Стороны вправе заключить договор в форме, которая предусмотрена законом для совершения сделок. Это может быть традиционный подписанный сторонами документ или согласование условий в результате обмена документами в электронном формате, позволяющим достоверно идентифицировать авторство и адресатов документов.

Как такового электронного ДДУ закон не предусматривает, предполагается его электронная регистрация, подписание ЭЦП, сбор в цифровом формате документов, информации о кадастровом номере, оценке недвижимости, о застройщике и его покупателе. Аналогичные положения содержатся и в других нормативных правовых актах. Так, из положений статей 312.1 и 312.2 ТК РФ следует, что договор с работником, который трудится удаленно, может быть оформлен в электронной форме. В ст. 312.2 ТК РФ указано на то, что при оформлении удаленной (дистанционной) работы трудовой договор, равно как и соглашения об изменении его условий могут быть заключены посредством обмена электронными документами [5]. Обратим внимание, что здесь, как и в нашем случае, нет прямого указания на электронный договор, а лишь на возможность обмена документами в цифровом формате. В то же время, этот формально обеспечивающий подход, предоставляет широкое применение для цифровых технологий.

Электронный ДДУ, как и любой иной электронный договор нельзя считать особым видом (типом) договора, так как к его регулированию применимы те же нормы, что и к традиционному договору, выполненному в аналоговом (бумажном, не в цифровом) формате, принимая во внимание, что стороны, предмет договора и его существенные условия не меняются. 
Обратим внимание на то, что электронный документооборот предполагает некоторое видоизменение процедур традиционного способа заключения договора. В этом смысле электронный договор нельзя считать каким-то новым или особым видом договора, а лишь одним из способов его заключения [6, с. 749].

Такой способ требует особой правовой регламентации. Применительно к ДДУ, как и иным сферам применения электронных договоров, в качестве основы могут быть использованы разработанные в 2012 г. Ассоциацией российских банков (АРБ) «Рекомендации по заключению электронных договоров». Документ предусматривает два базовых условия электронной формы заключения договора. Это подписание сторонами и их удостоверение. Первое условие исходить от понятия акцепта, т.е. ответа того, кто получил предложение заключить договор. Традиционно акцепт всегда выражался письменно, но возможен также вариант исполнения отражённых в оферте условий договора. Для аналоговой формы, процедуры установления (подтверждения) личностей сторон давно и прочно закреплены, тогда как для цифровой формы они активно обсуждаются, что связано с противоречивой практикой применения ЭЦП. Её совершенствование способно обеспечить развитие практик электронного ДДУ, что существенно, особенно в условиях возможного повторения ограничений, упростит практику заключения этого вида договоров, хотя, вероятно, и не заменит традиционную форму, к которой потребитель также в силу традиции и большей защищенности, доверяет в большей степени.

\section{ЛИТЕРАТУРА}

1. Калошина С.В., Некрасова М.В. Риски участников строительства в условиях экономического кризиса// Юрисконсульт в строительстве. 2017. № 4. С. 60-64.

2. Кысыкова Г.Б., Жаксылыкова А.К. К вопросу о совершенствовании механизмов долевого участия в жилищном строительстве// Вестник Института законодательства и правовой информации Республики Казахстан. 2020. № 3 (61). C. 66-74. https://www.elibrary.ru/download/elibrary_43847400_39589974.pdf

3. Александрова В.С. Заключение электронного договора с использованием интеллектуальных агентов (электронных агентов)// Право и бизнес: правовое пространство для развития бизнеса в России. Колл. монография. В 4-х т. М., 2020. С. 250-255.

4. Гражданский кодекс РФ (часть І) от 30.11.1994 г. № 51-Ф3 (ред. 09.03.2021) // Собрание законодательства РФ. 1994. № 32. С. 3301.

5. Трудовой кодекс Российской Федерации от 30.12. 2001 г. № 197-Ф3 (ред. 18.12.2020 г.) // Собрание законодательства РФ. 2002. № 1. Ст. 3.

6. Бахтина Ю.С., Ашурова Э.А. Особенности заключения гражданско-правовых договоров в электронной форме// Аллея науки. 2018. Т. 4. № 6 (22). С. 748755. https://elibrary.ru/download/elibrary_35326937_71929604.pdf

○ Иванов Алексей Алексеевич (ExeleX001@mail.ru). 